\title{
Exploring Searching as Evidence of Development in Interactional Competence
}

\author{
Du $\operatorname{Re} \operatorname{Kim}^{\dagger}$ \\ Jamsin High School
}

\begin{abstract}
In order to identify the critical features of interactional competence (IC) constructs and discuss IC development, this paper describes and analyzes how L2 speakers at different proficiency levels perform searching during talk-ininteractions. Although all L2 participants, regardless of their proficiency, successfully manage problems to keep talk progressing, they display different features in the way they initiate and complete searching. More proficient L2 participants explicitly deploy substantial linguistic and interactional resources such as L1 or a direct request for help, clearly displaying that the searching action is underway. They also engage in searching not only to locate what is unavailable at the moment, but also to search for what is better suited to the context in order to proactively avert possible misinterpretations before they occur. This study suggests that one of the important features of IC is projecting ahead and dealing with potential problems so that speakers can tailor their talk to their recipients, and co-participants can share more interactionally and sequentially common ground as the interaction expands.
\end{abstract}

Keywords: searching, repair, interactional competence, conversation analysis, second language acquisition

\section{Introduction}

If what we know as language knowledge is really a dynamic, constantly evolving set of recurring regularities, the shapes of which emerge from their frequent and predictable use, and if use is fundamentally interactional, $\cdots$, then we need to begin our examinations with the interactional practices that learners are involved in (Hall, 2004, p. 610).

Participating in conversation requires not only an ability to use a set of linguistic knowledges in appropriate ways but also the ability to monitor ongoing speech, to

\footnotetext{
${ }^{\dagger}$ Corresponding author: dorothea0516@gmail.com
} 
provide relevant next actions, and to adapt our conduct contingent on others so that our talk can be more fitted and better comprehensible to the others. The same applies to L2 speakers. They should gradually develop their interactional competence (IC), or the ability "to recipient design talk and to deploy context-sensitive conduct ... better tailored to the local circumstantial details of the interaction" (Pekarek Doehler \& Pochon Berger, 2015, p. 262).

As a number of renowned academic journals, Language Assessment (2018), Classroom Discourse (2018), Journal of Pragmatics (2018) to name a few, have featured articles on IC, there has been a rapid growth in the research of IC, and its focus has shifted from conceptualizing IC to discovering significant features which can be the key evidence for IC development. L2 IC researchers thus have compared L2 conversations by speakers of different proficiency to discover distinctive interactional features in a specific interactional practice. Galaczi (2014), for example, found that L2 speakers with higher IC are likely to have long-lived, co-constructed topic development and strong listener supports while those with less developed IC tend to have short-lived topics with fewer supports. Lam (2018) also observed that more interactionally competent L2 recipients provide more contingent response while less competent recipients only minimally receive the previous talk. Roever \& Kasper (2018) discovered that L2 speakers with developed IC have tendency to use preliminaries, or pre-sequence, before displaying a target action with relevant background information rather than directly jumping to initiate the action. These studies are not for confirming a general assumption that L2 proficient speakers have higher IC but for discovering the important features of IC constructs, such as topic expansion, recipient contingency, or preliminaries. Such studies can be applied for developing instructional tasks which elicit these significant IC features (Plough, 2018), and for further development of assessment and rubric to measure IC. As such trend is still new in SLA, more studies to discover and elicit these IC features are required.

One of the classical ways of discovering IC features has been analyzing repair organization, as it describes the process that L2 participants, who possibly have limited proficiency, deal with troubles in talk to re-establish intersubjectivity. However, most of IC repair studies have investigated this practice as a whole (Hellermann, 2009, 2011) and have not specifically investigated a certain type of repair. Considering that there are different methods of repair resulting in different social actions, focusing on a specific type of repair may disclose more useful features of IC development (Skogmyr \& Marian Balaman, 2018). The present study therefore 
investigates searching, one type of self-initiated repair mostly found in second language conversation and becomes an important opportunity for learning (Brouwer, 2003), to elicit significant features of IC construct. The study also demonstrates how these distinctive features can account for "the diversification of methods for accomplishing social interaction" (Pekarek Doehler \& Pochon-Berger, 2015, p. 262), which leads to the discussion on IC development.

\section{Study Backgrounds}

\subsection{Interactional competence}

Hymes (1972) was one of the first scholars who asserted the importance of contextualized view of language use. He argued that competence does not only refer to speaker's cognitive knowledge but also involves how the speaker can use language in a specified context. Hymes (ibid.) called the ability to use language appropriately in a real situation communicative competence, which made contrast with Chomsky's (1965) linguistic competence, which refers to individual's underlying abstract system of language realized through actual production. Communicative competence became the basis for Canale \& Swain (1980) and Canale (1983), which differentiated four types of communicative competence: grammatical, sociocultural, discourse, and strategic competence. He \& Young (1998) further expanded this model by incorporating IC. While IC might simply appear as the fifth component of communicative competence, He \& Young (ibid.) accounted for the difference in that, while communicative competence is cognitive and static based on individual's knowledge, IC is distributed among conversational partners and co-constructed by all the participants in conversation. IC displays how the participants collaborate utilizing interactional resources together to maintain intersubjectivity throughout the interaction. That is, "IC is not what a person knows, it is what a person does together with others" (Young, 2011, p. 430).

As IC is "practice-specific" (Young, 2019, p. 93), meaning that it can be observed from speakers' participation in specific discursive practice repeatedly occurs in context, IC developmental studies have focused on a specific practice such as turn-taking, opening or closing of a story, or repairing. Since this study is about searching, a type of repair practice, the study would only explore L2 repair studies from the following chapter, but would like to cite the summaries of key findings 
in IC developmental studies from Pekarek Dohler \& Pochon-Berger's (2015, p. 262):

a. IC is not simply transferred from L1 to the L2 but is recalibrated.

b. Less proficient L2 speakers tend to start off with a highly limited set of techniques for accomplishing a given action.

c. Over time, these techniques become diversified.

d. The diversification implies both the sequential organization of actions and linguistic resources put to use.

e. The diversification of methods for accomplishing social interaction essentially involves a growing ability to recipient-design talk.

\subsection{Repair organization in L2 IC studies}

Speakers, whether in L1 or L2, routinely confront problems in everyday interactions, and how the speakers sequentially develop turns to resolve the trouble and re-establish mutual comprehension becomes the key factor to discover IC. For this reason, it is important to study repair organization for finding the evidence of IC development.

The seminal CA work on repair (Schegloff et al., 1977) explained that repair is sequentially organized process in which a part of talk is treated as trouble-source and a possible solution is followed, while some trouble-sources can go without being repaired. Repair can be initiated by the speaker who has uttered the repairable (self-initiated) or the co-participant (other-initiated), whereas a trouble is fixed either by the speaker who is responsible (self-repair) or by the co-participant (other-repair). Such distinction is critical, given that the participants in talk have "preference" for self-repair, in that a speaker who has produced a repairable has the priority to do any repair deemed necessary. The speaker gets the priority to fix the trouble while other-repair is mitigated, and such preference is the important clue for L2 IC development as the following studies have demonstrated.

Hellermann (2009) took both quantitative and qualitative approaches to find the evidence of IC development from one focal adult English learner. After analyzing the post-recycled format, the study found a gradual decrease of other-initiated repair but an increase in self-initiated repair. This study demonstrated that IC is closely related to L2 speakers' ability to monitor one's own talk and resolve problems before the other co-participant rectifies it as a problem. The study by Sert \& Balaman (2018) investigated policing actions as a repair practice when completing task through video 
chatting. The study found the evidence of IC development through how the participants evolve from other-policing to self-policing. In the beginning stage, when one of the participants showed divergence from the rule doing the task, the others rather abruptly interrupted and claimed the rule-breaking. However, in the later stage, they instantly noticed their own divergence and attempted to keep the rule before the others found the problem to collaboratively complete the given task.

IC repair research also has concentrated on the diversification of its practice. Hellermann (2011) explored how two L2 focal speakers changed their ways of other-initiating repair over fifty weeks. In early terms, repair initiation was centered on correcting linguistic problems such as lexical choices or pronunciation, but the orientation of repair moved to action projection in later terms. Moreover, after initiating repair with no, the speakers added accounts for possibly face-threatening nature of a denial, which showed more "felicitous use of language with and for action" (Hellermann, 2011, p. 166). Kim (forthcoming) investigated the usage of replacing, one type of self-initiated self-repair in which a speaker of trouble-source replaces it with the new item. This study showed that L2 speakers with more IC would likely to substitute the lexical item that has narrower range of meaning for the previous choice, so that they could avert the possible ambiguity in advance. In line with the previous studies, the current study attempts to find the critical features of IC development in searching, a type of repair which is major in L2 talk but has not yet been focused in L2 IC research.

\subsection{Searching as repair practice}

Searching refers to a type of repair in which "a speaker in interaction displays trouble with the production of an item in an ongoing turn at talk" (Brouwer, 2003, p. 535). Searching has been profoundly studied in L1, especially in conversation analysis (CA) (Schegloff et al., 1977; Schegloff, 1979; Schegloff, 2013). It is forward-oriented self-repair in which a speaker halts to find the item due next to complete the turn projected so far. Goodwin \& Goodwin (1986) and Schegloff et al. (1977) found that word search frequently involves non-lexical perturbation such as $u h s$, vowel stretches, or pause, to signal the initiation of repair. After searching is done either by self (self-initiated self-repair) or by other (self-initiated other-repair), the participants in talk close the searching sequence and go back to the main sequence (Schegloff et al., 1977; Lerner, 1996).

Lerner (1996) analyzed the practice of word searching in terms of progressivity. 
When a current speaker does not move forward to complete the turn construction unit (TCU) under way, it makes a slot in which a specific grammatical type of item is appropriate, such as a verb, a verb complement, or an object. Native speakers frequently design their turn so that searching can be positioned at TCU-endings, which makes it easier for a recipient to join and complete the repair.

Early classical L2 studies have viewed searching as a type of communication strategies to compensate for L2 learners' linguistic deficiency in speaking. The study by Dörnyei (1995, p. 58) listed a number of compensation strategies such as circumlocution (describing the target object), approximation (resorting to an alternative item), or code-switching (using L1), most of which are to be used when the target word that an L2 speaker should use is unavailable due to insufficient L2 knowledge.

With a growing emphasis on the interactional dimension of second language (e.g., Firth \& Wagner, 1997, 2007), a research focus has turned from pointing out the lexical incompleteness of the learners to observing the creative process of searching through interaction with peers. Brouwer (2003) found that word searching sequence can provide language learning opportunities in the interaction between L1 (expert) and L2 (novice) speakers. Kurhila (2006) showed that L2 speakers provide L1 speakers with phonetic clues or possible alternative so that L1 speakers collaborate to complete word search activity. The study by Hosoda (2006) observed that L2 speakers, after self-initiated self-complete word searching, frequently halted turn-in-progress to request confirmation to L1 speakers on the target word. These studies have closely investigated how the L2 speakers, regardless of their proficiency, find problems in searching and solve them in a joint activity through collaborative sequence of talk.

Although the former research demonstrated successful interaction of L2 participants in their ways of doing searching, little research so far has focused on searching in the context of IC development. Considering a rapidly expanding trend of IC, it is important to discover more features of IC from this major type of repair. This study thus attempts to answer the following research question: What distinctive features in searching can be found from L2 speakers with different proficiency, and how such distinctions can account for IC development? 


\section{Methodology}

\subsection{Participants with different L2 proficiency}

A number of prior IC developmental studies have compared how speakers with different L2 proficiency display distinctive IC features in their discursive practices and analyzed how such difference can be a critical evidence of IC development (Galaczi, 2014; Lam, 2018; Roever \& Kasper, 2018). Likewise, the current study took cross-sectional approach to discover distinctive features of searching from L2 interaction. The study found L2 participants of different English proficiency by posting the recruiting letters to a few college websites and English study groups. They submitted the proof of their score in a standard speaking test for L2 speaking proficiency (cf. Galaczi, 2014; Kim, forthcoming) and the length of residence in English-speaking countries for more possibility of intensified interaction in a target language (cf. Bella, 2012). Twenty-four Korean college students were divided into three groups according to these two standards, and further divided into four members in one group to promote intensive interaction (Long \& Porter, 1985). Some of the participants in a group knew each other as they went to the same school, the same study group, or the same church. They were studying for various academic disciplines, but none of them were specialized in English or other language-related fields. Each group met at an empty college classroom and had an ice-breaking time before the actual recording so that they could feel comfortable talking in English. They talked about two general topics, English learning and traveling for about thirty minutes each, which was recorded by one of the participants. The participants did not know the purpose of the study at the time of recording, and they received monetary rewards for taking part in the study and consented to using their data. More detailed information of the participants can be found in the following Table 1 . 
Table 1. Participants of the study

\begin{tabular}{|c|c|c|c|c|}
\hline Group & $\begin{array}{l}\text { Participants } \\
\text { (pseudonyms) }\end{array}$ & $\begin{array}{l}\text { Recorded time } \\
\text { (min. : sec.) }\end{array}$ & $\begin{array}{c}\text { Score in TOEFL } \\
\text { speaking } \\
\end{array}$ & Length of residence \\
\hline $\begin{array}{l}\text { Novice A } \\
\text { Novice B }\end{array}$ & $\begin{array}{l}\text { Abby, Adam, } \\
\text { Anna, Aria } \\
\text { Bella, Beth, } \\
\text { Blair, Bob }\end{array}$ & $\begin{array}{l}\text { English 29:15 } \\
\text { Travel 31:15 } \\
\text { English 27:13 } \\
\text { Travel 29:43 }\end{array}$ & $\begin{array}{l}\text { Average: } 19.62 \\
\text { SD (Standard } \\
\text { Deviation): } 1.06\end{array}$ & Less than six months \\
\hline $\begin{array}{l}\text { Intermediate A } \\
\text { Intermediate B }\end{array}$ & $\begin{array}{l}\text { Caleb, Carlos, } \\
\text { Celia, Cora } \\
\text { Daisy, Dan, } \\
\text { Diana, Dylon }\end{array}$ & $\begin{array}{l}\text { English } 35: 40 \\
\text { Traveling 32:55 } \\
\text { English 29:53 } \\
\text { Travel 33:29 }\end{array}$ & $\begin{array}{l}\text { Average: } 23.12 \\
\text { SD: } 1.12\end{array}$ & $\begin{array}{l}\text { More than a year but } \\
\text { less than two years }\end{array}$ \\
\hline Advanced A & $\begin{array}{l}\text { Ella, Ethan, } \\
\text { Everly, Ezra } \\
\text { Faith, Fiona, } \\
\text { Fred, Frida }\end{array}$ & $\begin{array}{l}\text { English 43:11 } \\
\text { Travel 28:58 } \\
\text { English 37:28 } \\
\text { Travel 33:47 }\end{array}$ & $\begin{array}{l}\text { Average: } 27 \\
\text { SD: } 1.31\end{array}$ & More than three years \\
\hline
\end{tabular}

\subsection{Data transcription and CA}

To demonstrate whether L2 speakers have and how they have developed IC, IC scholars have adopted ethno-methodological framework of CA. According to Garfinkel (1967), the goal of ethno-methodology is to find methods, the practices that the members of a society take for granted to accomplish social actions. The works of CA-SLA (Kasper \& Wagner, 2011) argued that IC could be understood in terms of such methods that are perceptible and recognizable by others to accomplish their actions, and the development of IC referred to a change of such methods in a way to be more comprehensible for others and suitable for the contexts (Hellermann, 2008; Pekarek Doehler, 2010; Hall, Hellermann \& Pekarek Doehler, 2011). Theoretical backgrounds of IC are aligned with CA based approach. Instead of a fixed and static assumption, "CA presents competence as variable and co-constructed by participants in interaction" (Seedhouse, 2011, p. 348). IC scholars have agreed that competence not only refers to individual's knowledge in the formal system of linguistic rules, but also involves how L2 co-participants collaborate to co-construct intersubjectivity in talk-in-interaction. CA has great implications in SLA for viewing talk-in-interaction by L2 speakers as achieving order and social organization and taking learning as socially distributed knowledge among the co-participants (Kasper \& Wagner, 2011; Waring, 2017). Wong (2013) even argued that SLA researchers no longer need to "advocate for CA as the phrase CA-for-SLA or CA-SLA imply" (p. 16). For this reason, the primary tool for analyzing the data in the study is CA 
for a detailed description of interactional process in searching. CA allows the researcher to capture all the details of interaction, even to non-lexical resources such as a pause or sound stretches, with its fine-grained transcription system. The recorded data was transcribed using CA convention (see Appendix), and the episodes of talk in which a speaker halts a speech possibly displaying trouble in producing the next item due were analyzed from the data set.

All the episodes of halting of speech for finding the next item due were counted and analyzed. Since the focus of this study was lexical search, which is forward-oriented self-repair (Schegloff, 1979; Carroll, 2006), the study involved neither self-repair to correct what had been wrongly produced (backward-oriented) nor the process of grammatical search. The study also did not include speech perturbations occurred in TCU (turn construction unit)-beginnings, as there can be "pre-beginnings" (Schegloff, 1996, p. 24) such as turn-holding uhs or appositionals (e.g., well, so, and) which occur before the actual turn-beginnings to find more appropriate timing for transition without possible gaps or overlaps (Sacks et al., 1974; Schegloff, 2000). Additionally, the study did not consider the usage of hesitation or hedgings resulted from dispreferred actions (Pomerantz, 1984).

\section{Data Analysis and Discussions}

\subsection{Three types of searching and frequency}

After analyzing searching episodes by L2 participants, the study found three features of searching that were prevalent in each proficiency group: implicit searching in novice group, explicit searching in intermediate group, and proactive searching in advanced group. This section introduces each feature in detail and its frequency.

Firstly, implicit searching under this study refers to use of $u$ h/um or pause, which marks the points of interruption but does not explicitly display the item being under searched. Schegloff et al. (1977) observed that these non-lexical perturbations can be categorized into "repair-initiators" (p. 367) which are used to signal that word searching is under way. It is therefore necessary to point out here that both explicit and proactive searching sequentially follow implicit searching. When the next item is unavailable at the moment, the speakers used these initiators to gain extra time in searching (Rieger, 2003; Carroll, 2006). 
(1) Novice Group B

01 Bla: watching the drama (1.0) is to learn uh uh

02 $\rightarrow \quad$ English skill and u:h (2.0) relax relax

(2) Advanced Group B

01 Fio: um actually my expression was they made it

$02 \rightarrow \quad$ very um (1.0) uh fan- fancy? for the tourism?

Blair in (1) produced $u: h$ and gap before reaching the target item relax (line 02), and Fiona in (2) as well started searching with $u m$, a pause, and $u h$ before finding the word fancy (line 02). They implicitly displayed that searching was being progressed but did not explicitly produce any linguistic clue regarding the target item being searched.

Whereas some participants searched only using non-lexical remarks, some speakers progressed to the next stage of using substantial lexical elements to do more active searching. Explicit searching in this paper refers to speakers' searching with the actual use of lexical resources, such as part of a target item, L1 equivalent, or metalinguistic request after implicit searching. This searching occurs when the participants provide lexical clues for the recipients to resolve searching, although it does not necessarily mean the recipients successfully found the item.

(3) Novice Group B

01 Bob: okay so do you have play and plan to study

$02 \quad$ English in the future?

03 Bel: no I don't have I don't have plan but I just I

04 $\rightarrow \quad$ just English as um (1.0) 평소대로?

phyeng.so.day.lo. (as usual)

05 Bob: okay. 평소대로.

phyeng.so.day.lo. (as usual)

As shown in (3), when Bella failed to find the appropriate next item to complete the current TCU, she switched code to produce L1 (line 04), possibly being unable to find the target item in L2, which was sequentially received by Bob in the next turn (line 05). 
(4) Intermediate Group B

01 Dan: South European people is more uh active they real

02 really like to play with other people so that the

03 $\rightarrow \quad$ end of the ur the musical they uh what is audi

04 Dai: audience?

05 Dan: yes audience.

When Dan in (4) did not progress to complete the current TCU, he explicitly asked for a help in searching along with a partial phonetic information on the target item (what is audi-, line 03). Such direct request and a partial production of the target item (audi) invited Daisy to complete searching in the next turn, providing the appropriate item (audience, line 04), to which Dan accepted in the next turn to complete his turn (self-initiated other-repair).

Thirdly, proactive searching is different from the two previous ones in that L2 speakers did searching even when the target item due was available. L2 advanced speakers halted their talk sometimes and added metalinguistic remarks to confirm if searching activity was comprehensible for the recipients.

(5) Advanced Group B

01 Fri: and all the all the visitors who go through the

02 castle they wore real d- u:h (1.0) do we call it

03 $\rightarrow \quad \cos$ [tumes?

04 Fre: [costumes. right.

Frida in (5) halted when she reached they wore real and began searching for the next item to finish her turn. Frida did find the target word costumes but uttered metalinguistic remark (we call it) to receive confirmation from the recipients if her choice of the word was appropriate. Such searching technique was not initiated by an unavailability of a target word but by a proactive action to avert a possible trouble which might occur from the choice of a word.

The three features of searching practice introduced in the study so far by no means imply that only these features were found in the data. The present study focuses on these three searching features because, as demonstrated in the following Table 2 , the inductive analysis revealed that there was significant difference in its frequency. 
Table 2. Frequency of each feature (for about every 1000 word)

\begin{tabular}{cccc}
\hline Searching & Implicit searching & Explicit searching & Proactive searching \\
\hline \hline Novice & 15.02 & 1.68 & 0 \\
Intermediate & 5.55 & 2.22 & 0 \\
Advanced & 1.15 & 1.51 & 1.14 \\
\hline
\end{tabular}

Implicit searching was mostly used by L2 participants, but it occurred most frequently in novice speaker groups and advanced speakers showed much less usage. While there is a huge gap in its frequency, explicit searching was the second mostly found feature by L2 participants. Intermediate speakers frequently used explicit searching by asking for a request or providing clues by switching codes when the target item was not available. Novice L2 speakers did use explicit searching but its frequency was much lower than that of implicit searching. Proactive searching was only found in advanced group and they showed most diversified techniques in searching as found in Pekarek Doehler \& Pochon-Berger's (2015). Then, how such different features of searching leads to the discussion of IC development?

\subsection{Qualitative analysis and discussion}

\subsubsection{Clarifying searching activity}

The previous section displayed that participants in general used implicit searching and the speakers in most cases were able to find the item after repair-initiators. For the discussion of IC development, however, the study would focus on the cases in which the target item was not instantly found. Table 2 displayed that among three groups, novice L2 speakers heavily deployed these speech perturbations on their way of searching.

(6) Novice Group A

01 Ann: I- I my my cousin is live in uh America? so I um

02 $\rightarrow \quad$ (3.0) I- I (7.0) I u:h ${ }^{\circ}$ 아 뭐지 ${ }^{\circ}$ you um (2.0)

a.moy.ci. (ah what is it?)

03 Ari: ask?

04 Ann: yeah? as- ask about the uh uh how I ca:n uh speak

$05 \quad$ English well

06 Ari: ah 
07 $\rightarrow$ Ann: she said uh uh memo? uh I I- uh=

08 Ari: =what.

$09 \quad(5.0)$

$10 \rightarrow$ Ann: what is 암기 in=

am.ki. (memorization)

11 Ari: =memorize?

12 Ann: memorize about the words.

From the preceding conversation of (6), Anna attempted to introduce a good English studying method told by her cousin (line 01). She extended a current turn but even after a series of gaps and repeats, she could not progress the current turn (see the long gaps in line 02). Her self-direct talk in L1 (line 02) indicates that she could not find the English equivalent. After a pause, Aria (line 03) provided the possible next word ask which Anna received in the next turn (line 04). Anna (line 07) initiated another repair with $u h$ while producing an incomplete word (memo) and still repeated $I$ and deployed $u h$, which demonstrated the speaker was still searching for the appropriate next items due. Aria offered to help (line 08) in a latched next turn and after a long pause (line 09), Ann asked for a direct help in L1 (line 10). Aria helped to complete the repair (line 11) based on the L1 resource and Anna took the item memorize to complete her turn in progress (line 12). Although this excerpt indicated that the novice L2 speakers could complete their turn-in-interaction using the whatever interactional resources at hand to maintain the intersubjectivity, it showed that novice L2 speaker did not explicitly ask for what was needed. Going back to line 2, the speaker only repeated $I$ but did not give further clue for the recipients to collaborate, which resulted in a long gap for almost seven seconds. Anna also searched for the corrective linguistic form of the target (line 07) but she did not use substantial linguistic resource to explicitly ask for her target word (line 09). Her searching sequence was complete only after Anna used L1 to clearly ask for a help (lines 10-12). In other words, implicit searching did display searching was under way but did not provide enough clue for the recipients to understand the target item unavailable to the speaker. There were few substantial linguistic resources for the participants to collaborate, which resulted in a longer sequence of repair. That is, Anna's method of searching was not designed for the recipients. We can see the difference more clearly by examining how L2 intermediate speakers resolved searching in the following (7). 
(7) Intermediate Group A

01 Car: I try to question the uh professor in English

$02 \rightarrow \quad$ because it is the uh obli- obli- 의무

uy.mu. (obligation)

03 Cal: oh.

04 Car: yeah we [cannot

05 Cal: [obligation or responsibility.=

06 Car: =ask in Korean when I we want to have question.

L2 intermediate participants also started searching with implicit searching markers. The participants here were talking about the mandatory lectures taught only in English and from the preceding talk, Carlos complained that he did not want to ask questions in English. Carlos started searching for the next item due (line 02) with $u$ h and a repeat of cut-off (obli-) and provided L1 equivalent for the target word. Receiving the confirmation of comprehension by Caleb (oh, line 03), Carlos expanded his turn talking more about his experience, which was cut by Caleb (line 05) who provided the possible resolution for the repair remained unsolved, and Carlos (line 06) held the floor to continue from where he left off. When the target item was unavailable, the speaker produced L1 without a long gap so that the searching repair could be efficiently done. The speaker also provided partial information of the target word so that the recipient instantly picked up the next item due for him. Even though there was a communication problem which blocked the progress of the talk, the speaker and the recipient effectively collaborated to resolve the problem by using linguistic resources such as a part of the target word (obli-), L1 equivalent (ui.mu), and possible L2 solution (obligation or responsibility).

(8) Intermediate Group B

01 Dan: it is really super power to become u:h hh bilingual.

02 $\rightarrow$ Dyl: oh it's like uh absot- uh 절대음감?

jul.tay.um.kam. (absolute pitch sense)

03 Dan: yes maybe.

Dan was talking about being a bilingual in (8) and Dylon asked whether it was comparable to having a perfect pitch. Dan initiated searching by cutting off his first attempt absot- and switched to L1 word instead for the recipients (line 02). He raised the replaced item to check the comprehension ("try marking," Sacks \& Schegloff, 
1979), and the recipient did not take it further as a repairable but accepted L1 as the resolution for searching (line 03). When the target item was not available, the speaker did not just take time to keep searching. Rather, L2 intermediate speakers directly and clearly displayed their searching activity by producing L1 which helped the recipients to understand speakers' not-yet-projected turn and completed searching activity. In other words, searching by L2 intermediate speakers were more designed for the recipients to anticipate the projected action.

(9) Novice group A

$01 \mathrm{Abb}:$ uh uh wh- when we: study words?

02 Ann: $\mathrm{mm}$ :

03 $\rightarrow$ Abb: we're just (2.0) we're just uh uh uh

$04 \rightarrow(5.0)$

05 $\rightarrow$ Abb: u:h u::h

06 (all): hhh hh

$07 \rightarrow(2.0)$

08 Ann: group study is also good.

This data by novice group displays why explicit searching is more recipient-designed for maintaining mutual comprehension. Abby (line 01) launched her turn to talk more about studying vocabulary by producing a preliminary component (when we $\cdots$, line 01) to which Anna minimally received (line 02) to take the turn back for Abby to complete the compound (we just $\cdots$, line 03) (Lerner, 1996). However, Abby could not complete her turn (we just what?) but kept repeating uh (line 03). After a notable pause of about five seconds (line 04), she repeated uh with elongated vowels but again failed to progress her turn projected so far (line 05), and all the participants burst out a laughter (line 06). Abby neither directly asked for help to other speakers nor used L1 equivalent for repair completion. Abby did not explicitly display what she was searching again (line 07) and thus her action remained incomplete and interrupted by Anna (line 08), who started anew by taking the next turn to start a new topic.

The novice and intermediate speakers faced the problems with searching, and in most of the cases, the speakers solved the troubles on their own (self-initiated self-repair). Although searching may indicate their insufficient L2 lexical entry, the participants managed the troubles and progressed their talk. However, the evidence of IC development can be found from novice and intermediate speakers' searching. 
L2 novice speakers frequently did not progress further to provide substantial interactional resources which limited recipients' collaboration in searching the next item due. Intermediate L2 speakers, on the contrary, explicitly applied interactional resources for sense-making, such as L1, or a direct ask for help so that searching could be completed effectively and efficiently, without taking much time in going back to the main sequence. Intermediate L2 participants' searching displays that they were more "actively pursuing intersubjectivity in spite of trouble in language understanding and production" (Kasper and Wagner, 2011, p. 129).

\subsubsection{Searching as proactive activity}

The previous section discussed how the development of IC could be found in ways of managing searching under way. Contrary to novice L2 speakers, intermediate speakers displayed their searching activity with more substantial language, which made the recipients better understand turns projected so far and collaborate to complete repair. Advanced L2 speakers also clearly demonstrated their searching, such as using metalinguistic question as demonstrated in (10).

(10) Advanced Group B

01 Fre: but I found it's quite fascinating that um my

02 ancestr- I I'll say not only my ancestors hh. uh

03 were pioneers and like evening at the sky and

$04 \rightarrow \quad$ investigating at the uh (1.0) what was that?

$05 \rightarrow \quad$ astrology is it?=

06 Fio: =right.

Fred in (10) shared his recent trip to a historic place. While talking about his surprise in scientific advancement, he self-interrupted and paused (line 04) to initiate a repair, and overtly displayed his action of searching (what was that?). He did not let the other recipients take a turn but provided the target word immediately (astrology is it? line 05), which suggested that the target word was available for him but he did searching to check if his choice was appropriate. Fred's usage of such direct metalinguistic question guided his recipients to searching activity and clearly displayed his undergoing actions (e.g., searching, checking) in unfolding turn. 
(11) Advanced Group A

01 Eth: so uh I think the strong desire is very important to study English or whatever subjects. I think like that.

04 $\rightarrow$ Eve: $\quad$ yeah. you got real u:h >I'll say< passion?= 05 Ezr: =right. in some respect. passion.

Ethan in (11) told his recipients that he had a strong will to study English that he practiced speaking and writing every day. Everly (line 04) supported Ethan's hard work, and while doing that, he halted $(u: h)$ and displayed his searching evidently (I'll say) before finding his target word (passion). Ezra agreed to Everly's choice of word in a latched turn and repeated the item (passion, line 05).

Both intermediate and advanced L2 speakers showed their searching in an evident way for the recipients and the recipients could understand and follow the action projected under way. Advanced L2 speakers also used self-guiding comments to even clearly show searching, which was more diversified to be fitted for context (Pekarek Doehler \& Pochon-Berger, 2015).

More critical evidence for IC, however, could be found from the proactive function of searching. While searching does not necessarily mean language deficiency of speakers, considering that novice and intermediate L2 speakers frequently code-switched to L1 or only partially produced the target item, it can be said that a major number of searching resulted from insufficient lexical information on the target item (Koshik \& Seo, 2012). Searching done by L2 advanced speakers, however, were not necessarily caused by L2 problems. Going back to (10), while Fred successfully found the target word astrology, his searching (what was it?) functioned to receive a confirmation from the recipients. In (11), the target item passion was available for Everly, but he did searching (I'll say) on his way of finding more appropriate item. In both cases, searching was used not because the speaker had deficient knowledge for the target item but because the speaker pre-empted what could be problematic for the recipient in advance. Fred checked whether astrology was a corrective linguistic form and Everly checked whether passion was appropriate choice to describe Ethan's work before projecting more.

According to Mauranen (2006) and Kaur (2009, 2011), self-initiated self-repair can be divided into two functions: reactive and proactive. Retroactive repair is back-looking repair which is used to correct what has been wrong in the previous talk, while proactive repair is forward-looking repair which is used to prevent what 
can be wrong in advance. Schegloff (2013) once wrote an analogy to display two different types of repairs:

A suit that someone tries on may be torn at the underarm; this is a troublesource and is in need of repair. But it happens as well that there is nothing wrong with the outfit, but tailor remarks that it would be more flattering to the wearer if the lapel was a tad narrower (p. 46).

Novice and intermediate speakers repaired for searching because they could not find the appropriate linguistic item due next, whereas advanced speakers repaired to choose, among possible alternative resources, the more appropriate item for the context. In other words, proactive searching by advanced L2 speakers indicated that they were more interactionally competent in that they could project ahead and tailor their talk in accordance of the others. The next (12) also shows the case in which repair was used as a process of "delicate searching" (Schegloff, 2013).

(12) Advanced Group A

01 Ezr: so sometimes I studied uh late and walked around 02 $\rightarrow \quad$ her offi:ce $>$ w- we call it< 교무실?

gyo.mu.sil. (teachers' office)

Ezra in (12) talked about how he studied English and told one of his ways was to ask a lot of questions to his English teacher. He initially found the target item her office but rushed through to switch to searching for Korean equivalent for the target word. His first choice was not wrong but he still searched for better lexical resource in the context for better comprehension of his recipients. Ezra's searching was not caused by his lack of knowledge in the name of a place but caused by his recipient-designing talk in a way to be better comprehensible for the co-participants. His searching was thus used for a proactive and preventative purpose (Kaur, 2009; Kim, forthcoming), which is a significant clue for IC development.

\section{Conclusion}

The purpose of the study is to find the critical IC features which can display L2 speakers' IC development. The study especially focused on the cases in which a 
target lexical item was not found instantly. Novice speakers tended to use non-lexical perturbations and frequently did not progress to provide more lexical clues for the recipients to collaborate searching. Intermediate speakers were likely to utilize lexical resources for the recipients to resolve searching repair with the recipients. Advanced speakers further searched for a more appropriate item even when the target item due was available.

The evidence of IC development was observable through these distinctive features in two aspects: clarifying what is targeted for searching, and doing proactive searching. Firstly, more interactionally competent speakers, rather than remaining silent or hesitant, clearly displayed what item is being searched under way using substantial language such as L1, direct asking for a help, or giving a clue for the target word, so that the recipients can anticipate the next items due. The recipients engaged in searching and collaborated so that they could finish the repair and go back to the main sequence of talk. Secondly, more interactionally competent speakers did not only search for what was unavailable. They looked for the item that was more delicate and fitted to the context to avoid any possible ambiguities or misunderstanding in advance. L2 speakers therefore should be encouraged to explicitly demonstrate and to clarify their troubles for the recipients and to minutely tailor their talk in the eye of the recipients. The result of study also implies that L2 IC speaking task and assessment should be designed to elicit the ability to use explicit and substantial linguistic resource when initiating repair and the ability to preempt upcoming troubles ahead.

Schegloff (2007) argued "[E]verything is $\cdots$ a possible repairable or a possible trouble source" (p. 300). L2 repair, just as L1, is not just correcting what is wrong but also choosing what is more suitable among different interactional resources. The current study confirms that searching is not a process of displaying what is insufficient in L2 but a process of making their talk mutually acceptable contingent on others. Highly interactionally competent L2 speakers organize their social conducts in a way to be more acceptable and comprehensible in recipients' shoes, which confirms the fact that "key to the deployment of the various interactional practices is still the most general principle of recipient design" (Waring, 2018, p. 61).

\section{References}

Bella, S. (2012). Length of residence and intensity of interaction: modification in Greek L2 
requests. Pragmatics, 22(1), 1-39.

Brouwer, C. E. (2003). Word searches in NS-NNS interaction: opportunities for language learning? The Modern Language Journal, 87(4), 534-545.

Brouwer, C. E. (2004). Doing pronunciation: A specific type of repair sequence. In R. Gardner, \& J. Wagner (eds.) Second language conversations, (pp. 93-113). London: A\&C Black.

Canale, M. (1983). From communicative competence to communicative language pedagogy.

In J. C. Richard, and R. W. Schmidt (eds.) Language and communication (pp. 2-14). New York: Longman.

Canale, M. and Swain, M. (1980). Theoretical bases of communicative approaches to second language teaching and testing. Applied Linguistics, 1, 1-47.

Carroll, D. (2006). Co-constructing competence: turn construction and repair in novice-to-novice second language interaction (Doctoral thesis). University of York, United Kingdom.

Cekaite, A. (2007). A child's development of interactional competence in a Swedish L2 classroom. The Modern Language Journal, 91(1), 45-62.

Chomsky, N. (1965). Aspects of the theory of syntax. Cambridge, MA: MIT Press.

Dörnyei, Z. (1995). On the teachability of communication strategies. TESOL Quarterly, 29(1), 55-85.

Firth, A. \& Wagner, J. (1997). On discourse, communication, and (some) fundamental concepts in SLA research. The Modern Language Journal, 81(3), 285-300.

Firth, A. \& Wagner, J. (2007). Second/foreign language learning as a social accomplishment: Elaborations on a reconceptualized SLA. The Modern Language Journal, 91, 800-819.

Galaczi, E. D. (2014). Interactional competence across proficiency levels: how do learners manage interaction in paired speaking tests? Applied Linguistics, 35(5), 553-574.

Gardner, R. \& Wagner, J. (2004). Second language conversations. London: A\&C Black.

Garfinkel, E. (1967). Studies in ethnomethodology. New York: Prentice Hall.

Goodwin, M. H. \& Goodwin, C. (1986). Gesture and co-participation in the activity of searching for a word. Semiotica, 62, 51-72.

Hall, J. K. (2004). Language learning as an interactional achievement. The Modern Language Journal, 88(4), 607-612.

Hall, J. K., Hellermann, J., \& Pekarek-Doehler, S. (2011) L2 interactional competence and development. New York: Multilingual Matters.

He, A. W., \& Young, R. (1998). Language proficiency interviews: A discourse approach. Talking and Testing: Discourse Approaches to the Assessment of Oral Proficiency, 14, 1-24.

Hellermann, J. (2007). The development of practices for action in classroom dyadic interaction: focus on task openings. The Modern Language Journal, 91(1), 83-96.

Hellermann, J. (2008). Social actions for classroom language learning. London: Multilingual Matters.

Hellermann, J. (2009). Looking for evidence of language learning in practices for repair: A case study of self-initiated self-repair by an adult learner of English. Scandinavian Journal 
of Educational Research, 53(2), 113-132.

Hellermann, J. (2011). Members' methods, members' competencies: Evidence of language learning in longitudinal studies of other-initiated repair. in J. Hall, J. Hellermann, \& S. Pekarek Doehler (Eds.) L2 interactional competence and development (pp. 147-172). Clevedon: Multilingual Matters.

Hutchby, I., \& Wooffitt, R. (2008). Conversation analysis. Polity.

Hymes, D. (1972). Models of the interaction of language and social life. in J. Gumperz \& D. Hymes (eds). Directions in sociolinguistics: the ethnography of communication. (pp. 35-51). New York: Wiley Blackwell.

Kasper, G. \& Wagner, J. (2011). A conversation-analytic approach to second language acquisition, in D. Atkinson (ed.): Alternative approaches to second language acquisition (pp. 117-142). London: Routledge.

Kasper, G \& Wagner, J. (2014). Conversation analysis in applied linguistics. Annual Review of Applied Linguistics, 34: 171-212.

Kaur, J. (2009). Pre-empting problems of understanding in English as a Lingua Franca, in A. Mauranen and E. Ranta (Eds.): English as a lingua franca: Studies and findings (pp. 107-123). Cambridge: Cambridge Scholars publishing.

Kaur, J. (2011). Raising explicitness through self-repair in English as a lingua franca. Journal of Pragmatics 43(11), 2704-2715.

Kim, D. Forthcoming. Emergence of proactive self-initiated self-repair as an indicator of L2 IC development. Applied Linguistics. https://doi.org/10.1093/applin/amz047

Koshik. I., \& Seo, M. (2012). Word (and other) search sequences initiated by language learners. Text \& Talk, 32(2), 167-189.

Lam, D. M. (2018). What counts as "responding"? Contingency on previous speaker contribution as a feature of interactional competence. Language Testing, 35(3), 377-401.

Lerner, G. H. (1996). On the "semi-permeable" character of grammatical units in conversation: Conditional entry into the turn space of another speaker. In E. Ochs, E. A. Schegloff and S. A. Thompson (Eds) Interaction and grammar, (pp. 52-133). Cambridge: Cambridge University Press.

Long, M. \& Porter, P. (1985). Group Work, interlanguage talk, and second language acquisition. TESOL Quarterly, 19(2), 207-228.

Mauranen, A. (2006). Signaling and preventing misunderstanding in English as lingua franca communication. International Journal of the Sociology of Language, 177, 123-150.

Pekarek Doehler, S. (2010). Conceptual changes and methodological challenges: On language and learning from a conversation analytic perspective on SLA. In P. Seedhouse, S. Walsh, \& C. Jenks (Eds) Conceptualising learning in applied linguistics (pp. 105-126). New York: Palgrave Macmillan.

Pekarek-Doehler, S. \& Pochon-Berger, E. (2011). Developing "methods" for interaction: a cross-sectional study of disagreement sequence in French L2. in J. Hall, J. Hellermann, and S. Pekarek Doehler (Eds.) L2 interactional competence and development (pp. 206-241). 
Clevedon: Multilingual Matters.

Pekarek-Doehler, S. \& Pochon-Berger, E. (2015). The development of L2 interactional competence: evidence from turn-taking organization, sequence organization, repair organization and preference organization. In T. Cadierno \& S. Eskildsen (Eds). Usage-based perspectives on second language learning (pp. 233-270). Amsterdam: De Gruyter Mouton.

Pekarek Doehler, S. \& Berger, E. (2018). L2 interactional competence as increased ability for context-sensitive conduct: A longitudinal study of story-openings, Applied Linguistics, 39(4), 1-25.

Pomerantz, A. (1984). Agreeing and disagreeing with assessments: some features of preferred/ dispreferred turn shaped. In J. Atkinson \& J. Heritage (Eds.) Structures of social action (pp. 57-101). Cambridge: Cambridge university press.

Rieger, C. L. (2003). Repetition as self-repair strategies in English and German conversations. Journal of pragmatics, 35(1), 47-69.

Roever, C. \& Kasper, G. (2018). Speaking in turns and sequences: interactional competence as a target construct in testing speaking. Language Testing, 35(3) 331-355.

Sacks, H., Schegloff, E. A., \& Jefferson, G. (1974). A simplest systematics for the organization of turn-taking in conversation. Language, 50, 696-735.

Sacks, H. \& Schegloff, E. A. (1979). Two preference in the organization of reference to persons in conversation and their interaction. In G. Psathas (ed.) Everyday language: studies in ethnomethodology (pp. 14-21). New York: Irvington Publishers.

Schegloff, E. A. (1979). The relevance of repair to syntax-for-conversation. in T. Givon (ed.): Syntax and semantics 12: Discourse and syntax (pp. 261-288). New York: Academic.

Schegloff, E. A. (1996). Turn organization: one intersection of grammar and interaction. In E. Ochs, E. A. Schegloff, \& Thompson, S.A. (Eds.) Interaction and grammar (pp. 52-133) Cambridge: Cambridge university press.

Schegloff, E. A. (2000). Overlapping talk and the organization of turn-taking for conversation. Language in Society. 29(1), 1-63.

Schegloff, E. A. (2007). Sequence organization in interaction: Volume 1: A primer in conversation analysis (Vol. 1). Cambridge University Press.

Schegloff, E. A. (2013). Ten operations in self-initiated, same-turn repair. In M. Hayashi, G. Raymond, \& J. Sidnell (Eds.) Conversational repair and human understanding (pp. 41-70). Cambridge University Press.

Schegloff, E. A., G. Jefferson, and H. Sacks. (1977). The preference for self- correction in the organization of repair in conversation. Language, 53(2), 361-382.

Seedhouse, P. (2011). Conversation analytic research into language teaching and learning. E. Hinkel (ed). The handbook of research in second language teaching and learning, (pp. 345-363). New York: Routledge.

Sert, O., \& Balaman, U. (2018). Orientations to negotiated language and task rules in online L2 interaction. ReCall, 30(3), 355-374.

Skogmyr Marian, K. and Balaman, U. (2018). Second language interactional competence and 
its development: An overview of conversation analytic research on interactional change over time. Language and Linguistics Compass, 12(8), e12285.

Waring, H. Z. (2017). Conversation analytic approaches to language and education. In K. King K., Y. Lai, \& S. May (eds) Research methods in language and education. Encyclopedia of language and education (pp. 1-10). Springer International Publishing.

Waring, H. Z. (2018). Teaching L2 interactional competence: problems and possibilities. Classroom Discourse, 9(1), 57-67.

Watanabe, A. (2017). Developing L2 interactional competence: increasing participation through self-section in post-expansion sequence. Classroom Discourse, 8(3), 271-293.

Wong, J., and Waring, H. Z. (2010). Conversation analysis and second language pedagogy: A guide for ESL/EFL teachers. New York: Routledge.

Young, R. (2011). Interactional competence in language learning, teaching, and testing in E. Hinkel (Ed.): Handbook of research in second language teaching and learning (pp. 426-443). New York: Routledge.

Young, R. (2019). Interactional Competence and L2 Pragmatics. In N. Taguchi (Ed.) Routledge handbook of second language acquisition and pragmatics (pp.93-110). New York: Routledge.

\section{Appendix}

Transcription conventions (adapted from Wong and Waring, 2010, xv)

falling intonation

? $\quad$ rising intonation

- abrupt cut-off

: $\quad$ prolonging of sound

word stress

OwordO quiet speech

$>$ word $<\quad$ quicker speech

$<$ word $>\quad$ slowed speech

hh aspiration or laughter

[word] beginning and ending of overlapping speech

$=\quad$ continuing speech with no break in between

length of a silence in tenths of a second

(word) transcriptionist doubt 
Du Re Kim

English Teacher

Jamsin High School

24 Jamsil-ro, Songpa-gu, Seoul 05502, Korea

dorothea0516@gmail.com

Received: February 14, 2020

Revised version received: March 29, 2020

Accepted: April 17, 2020 